\title{
STOICHIOMETRIC CHARACTERISTICS OF THE ROOT, STEM, AND LEAF OF SOPHORA ALOPECUROIDES L. IN THE DIFFERENT HABITATS OF THE YILI VALLEY, XINJIANG, CHINA
}

\author{
LIU, S. Q. ${ }^{1,2}-$ CUI, D. $.^{1,2^{*}}-$ YAN, J. J. ${ }^{1,2}-$ NIJAT, K. ${ }^{1,2}-$ YANG, H. J. ${ }^{1,2,3}$ \\ ${ }^{1}$ Institute of Resources and Ecology, Yili Normal University, Yining 835000, China \\ ${ }^{2}$ College of Biology and Geography Sciences, Yili Normal University, Yining 835000, China \\ ${ }^{3}$ Ministry of Education Key Laboratory of Vegetation Ecology, Institute of Grassland Science, \\ Northeast Normal University, Changchun 130024, China \\ *Corresponding author \\ e-mail: cuidongw@126.com
}

(Received $6^{\text {th }}$ Aug 2020; accepted $19^{\text {th }}$ Nov 2020)

\begin{abstract}
This study selected Sophora alopecuroides L. in the degraded grassland of the Yili Valley as the research target, the comparisons of the stoichiometric ratios of C:N, C:P, N:P before and after Sophora alopecuroides invasion in the soil were analyzed, and the eco-stoichiometry of the root, stem, and leaf of the plant in the different habitats (forest, roadside, farmland, desert) was discussed, as well as effects of habitats and organs on eco-stoichiometry of Sophora alopecuroides. The results showed that concentrations of $\mathrm{C}, \mathrm{N}, \mathrm{P}$ and their stoichiometric ratios in roots, stems and leaves changed with habitat, and only the concentrations of $\mathrm{N}$ and N:P ratios were in the order of leaves $>$ stems $>$ roots. The ratios of $\mathrm{C}: \mathrm{N}$ and $\mathrm{C}: \mathrm{P}$ were negatively correlated with the corresponding $\mathrm{N}$ and $\mathrm{P}$ concentrations. The $\mathrm{N}$ concentration was positively correlated with the $\mathrm{P}$ concentration, indicating a consistent demand of $\mathrm{N}$ and $\mathrm{P}$ during Sophora alopecuroides growth. According to the factorial analysis of the general linear model (GLM), we concluded that $\mathrm{C}: \mathrm{N}$ ratio and the $\mathrm{N}$ concentration are mainly affected by the organs, while the $\mathrm{P}$ concentration and C:P ratio are mainly affected by the habitats.
\end{abstract}

Keywords: plant, ecological stoichiometry, environment, organ, nutrient utilization

\section{Introduction}

Carbon, nitrogen and phosphorus are the basic chemical elements needed by plant growth. Carbon is the element with the highest dry matter concentration in plant corpus. Nitrogen and phosphorus are the important components of protein, enzyme and genetic material in cells and the basic elements of organisms (Wang and Yang, 2013; Ou et al., 2006). The ratio of N:P in plants can be used as an indicator to judge the adaptation of plant growth to nutrient supply (Wang et al., 2011). In the field of ecological research, chemometrics is usually applied to the study of the main elements of organisms (Aerts and Chapinf, 2000). Ecological stoichiometry is a new discipline to explain the balance of various chemical elements in ecological interaction. In the field of ecological research, stoichiometric characteristics provide a new method to study the main element composition of organisms (Michaels, 2003; Elser et al., 2000; Zeng et al., 2013). Scholars at home and abroad have studied the relationship between plant nutrient elements and environment from different scales (Ashton et al., 2005; Yu et al., 2016). Li et al. (2014) and Luo et al. (2016) studied the stoichiometric characteristics of plants in different habitats, indicating that plants adjust nutrient utilization strategies to adapt to environmental changes, thus enabling them to have a strong ability to adapt to extreme environments. 
Sophora alopecuroides L. is a member of the genus Sophora in the PEA (pea) family. It is a perennial herbaceous plant (Yang and $\mathrm{Yu}, 1998$ ). It appeared in the desert regions of northwestern China (Ningxia, Xinjiang, Inner Mongolia, Gansu, Qinghai, Tibet, etc.) (Li et al., 2005), and grew mainly in sandy soil and various kinds of salt habitats. It has the characteristics of salt-resistance, drought resistance, and sand buried resistance. Because the seeds of Sophora alopecuroides can take root and germinate quickly in the wet sand, the underground rhizome can reproduce rapidly, the ability to spread is very strong (Liu et al., 2017). In the Yili region, a large area of the grassland was invaded and spread, forming single dominant community with simple structure and few companion species in degraded areas, leading to the decline of grassland quality and economic productivity, which has posed a threat to the farming and pastoral areas in the region, especially in the degraded grassland area (Lu et al., 2011). At present, there are many studies on the medicinal value (Shang et al., 2018; Shi et al., 2019) of Sophora alopecuroides and few studies on the ecological stoichiometry of each organ of Sophora alopecuroides in different habitats. This study analyzed the changes of $\mathrm{C}, \mathrm{N}$ and $\mathrm{P}$ elements and their stoichiometric ratios in roots, stems, and leaves of Sophora alopecuroides based on the different habitats, aiming to understand the ecological mechanism of the growth environment of Sophora alopecuroides and the adaptation mechanism of Sophora alopecuroides in the various habitats, to provide theoretical basis for the restoration and protection of degraded grassland ecosystem vegetation.

\section{Materials and methods}

\section{Experimental site}

The study site is located in the Yili valley of Xinjiang, China $\left(81^{\circ} 05^{\prime} \sim 91^{\circ} 09^{\prime} \mathrm{E}\right.$, $43^{\circ} 80^{\prime} \sim 43^{\circ} 84^{\prime} \mathrm{N}$ ), which is a typical mountainous grassland area. The climate of this region is a temperate continental climate and belongs to the semi-arid region. The average annual temperature is $9-11.1{ }^{\circ} \mathrm{C}$, the average annual precipitation is $250-551.7$ $\mathrm{mm}$ and the average annual evaporation is $1621 \mathrm{~mm}$. The altitude is $550-596.2 \mathrm{~m}$. In the study area, as shown in Figure 1, we selected the forest (plot-I, at an altitude of 579.1$588.4 \mathrm{~m}$ ), roadside (plot-II, 550-551.2 m), farmland (plot-III, 590-593.5 m) and desert (plot-IV, 596-596.3 m) invaded by Sophora alopecuroides (coverage up to 80\%).

\section{Sample collection}

The habitats invaded by Sophora alopecuroides layout for forest (plot-I), roadside (plot-II), farmland (plot-III) and desert (plot-IV). The soil difference analysis of the various habitats was shown in Table 1 . The $\mathrm{pH}$ value of plot-IV was significantly higher than that of plot-II and III. The nitrate nitrogen of plot-I was higher than that of plot-II, III and IV. The concentrations of total nitrogen and total phosphorus in plot-II was the lowest compared with plot-I, III and IV. There was no significant difference in total carbon and organic matter concentration in the four habitats. There was no significant difference in organic matter concentration in the four habitats. Each habitat was randomly set three quadrats $(5 \mathrm{~m} \times 5 \mathrm{~m})$. Sophora alopecuroides of uniform growth were randomly selected from the quadrat. The above-ground organs of Sophora alopecuroides were collected by the harvesting method and the root of Sophora alopecuroides were collected by the digging method. The root, stem, and leaf were cut into small pieces of $2-4 \mathrm{~cm}$. They were marked and put in an envelope, while it was 
taken to the laboratory to measure the concentration of the element in each organ. Soil samples were collected separately from habitats invaded by Sophora alopecuroides. Soil samples were collected at $10 \mathrm{~cm}$ intervals and 0-40 cm samples were collected. Each soil sample is about $500 \mathrm{~g}$. At the same time, soil samples without invasion of Sophora alopecuroides around each habitat were collected. The above samples are used for the determination of soil physical and chemical properties.
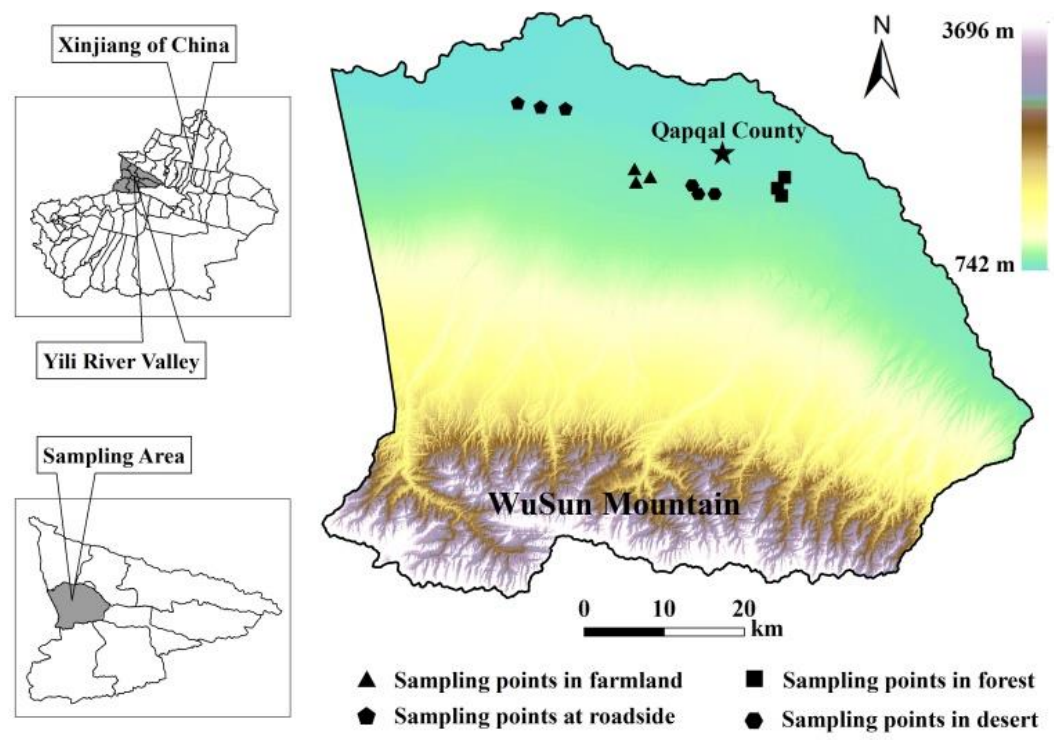

Figure 1. Sketch map of the study area

Table 1. Post-hoc test of soil physical and chemical properties in plot-I, II, III and IV

\begin{tabular}{c|c|c|c|c|c|c}
\hline Plots & $\begin{array}{c}\text { TN } \\
\left(\mathbf{g ~ k g}^{-1}\right)\end{array}$ & $\begin{array}{c}\text { TP } \\
\left(\mathbf{g ~ k g}^{-1}\right)\end{array}$ & $\begin{array}{c}\text { TC } \\
\left(\mathbf{g ~ k g}^{-1}\right)\end{array}$ & $\begin{array}{c}\text { Organic matter } \\
\left(\mathbf{g ~ k g} \mathbf{~ k g}^{-1}\right)\end{array}$ & $\mathbf{p H}$ & $\begin{array}{c}\text { Nitrate } \\
\text { nitrogen } \\
\left(\mathbf{m g ~ k g}^{-1}\right)\end{array}$ \\
\hline I & $1.06 \pm 0.10 \mathrm{ab}$ & $0.91 \pm 0.03 \mathrm{a}$ & $9.81 \pm 1.19 \mathrm{a}$ & $16.91 \pm 2.05 \mathrm{a}$ & $8.01 \pm 0.03 \mathrm{~b}$ & $6.73 \pm 1.07 \mathrm{a}$ \\
II & $0.48 \pm 0.02 \mathrm{c}$ & $0.64 \pm 0.05 \mathrm{~b}$ & $8.34 \pm 1.10 \mathrm{a}$ & $14.37 \pm 1.90 \mathrm{a}$ & $7.84 \pm 0.02 \mathrm{c}$ & $1.67 \pm 0.22 \mathrm{c}$ \\
III & $1.11 \pm 0.09 \mathrm{a}$ & $1.02 \pm 0.50 \mathrm{a}$ & $9.79 \pm 0.64 \mathrm{a}$ & $16.88 \pm 1.11 \mathrm{a}$ & $7.84 \pm 0.03 \mathrm{c}$ & $1.87 \pm 0.05 \mathrm{bc}$ \\
IV & $0.84 \pm 0.08 \mathrm{~b}$ & $0.71 \pm 0.20 \mathrm{~b}$ & $6.62 \pm 1.51 \mathrm{a}$ & $11.41 \pm 2.01 \mathrm{a}$ & $8.74 \pm 0.05 \mathrm{a}$ & $3.57 \pm 0.48 \mathrm{~b}$ \\
\hline
\end{tabular}

$\mathrm{TN}, \mathrm{TP}$, and TC represent total nitrogen, total phosphorus and total carbon; $\mathrm{a}, \mathrm{b}$, and $\mathrm{c}$ represent the significant characteristics of different organs in different habitats $(P<0.05)$

\section{Experimental method}

The root, stem, and leaf of Sophora alopecuroides were dried naturally, and all samples were dried to constant weight at $85^{\circ} \mathrm{C}$. Each organ of the sample was ground by a plant grinder, weighed and bagged for storage. The concentrations of total Carbon, total nitrogen and total phosphorus of Sophora alopecuroides were determined. The collected soil samples should be air-dried, and the roots and stones in the soil samples should be removed and bagged for testing. Total carbon, total nitrogen, total phosphorus, organic matter, $\mathrm{pH}$ and nitrate nitrogen of the soil were selected for the determination of soil physical and chemical properties. 
Soil and plant TC (Total Carbon) were determined by the potassium dichromate volumetric method (external heating method) (Lu, 1999). TN (Total Nitrogen) is determined by the perchloric acid sulfuric acid digestion method and by the Fuchs 1035 automatic nitrogen determinator ( $\mathrm{Lu}, 1999)$. TP (Total Phosphorus) was determined by acid-soluble molybdenum antimony anti colorimetry and Agilent Cary-60 UV spectrophotometer (Lu, 1999).

\section{Sample analysis and data processing}

The experimental data were processed using SPSS 24.0 and Excel 2010. The results were expressed by the mean and standard deviation (SD). One-way ANOVA was used to test the stoichiometric characteristics of $\mathrm{C}, \mathrm{N}$, and $\mathrm{P}$ in roots, stems, and leaves of Sophora alopecuroides and the differences of soil physical and chemical factors. Duncan's method was used for multiple comparisons, and the significance level was 0.05. The effects of different plots and organs on the $\mathrm{C}, \mathrm{N}$, and $\mathrm{P}$ concentrations were analyzed by GLM. The general linear model (GLM) was used to analyze the principal factor effects and interactions, and then the influence of each factor on the concentrations of $\mathrm{C}, \mathrm{N}, \mathrm{P}$, and their stoichiometric characteristics.

\section{Results}

\section{Comparison of the stoichiometric of $C, N$, and $P$ in soil samples}

The distribution of $\mathrm{R}_{\mathrm{CN}}\left(\mathrm{C}: \mathrm{N}\right.$ Ratio ), $\mathrm{R}_{\mathrm{CP}}\left(\mathrm{C}: \mathrm{P}\right.$ Ratio) and $\mathrm{R}_{\mathrm{NP}}(\mathrm{N}: \mathrm{P}$ Ratio) in the soil profile in the invaded and uninvaded soil of Sophora alopecuroides were shown in Figure 2. In the profile of the invaded soil, the $\mathrm{R}_{\mathrm{CN}}$ decreased obviously with the increase of depth, and the maximum of the $R_{C N}$ appeared in the $0-10 \mathrm{~cm}$ soil layer (Fig. 2A). The maximum of $\mathrm{R}_{\mathrm{CP}}$ was in the surface layer, the $\mathrm{R}_{\mathrm{CP}}$ in the $20-30 \mathrm{~cm}$ soil layer was slightly higher than that in the $10-20 \mathrm{~cm}$ soil layer (Fig. 2B), and the minimum of $R_{C N}$ and $R_{C P}$ appeared in the $30-40 \mathrm{~cm}$ soil layer. The $R_{N P}$ changed little, and the maximum of the $\mathrm{R}_{\mathrm{NP}}$ was in the $20-30 \mathrm{~cm}$ soil layer (Fig. 2C). In the profile uninvaded soil of Sophora alopecuroides, the $\mathrm{R}_{\mathrm{CP}}$ decreased with the increase of soil depth, the maximum of $R_{C N}$ appeared in $10-20 \mathrm{~cm}$ soil layer, and the maximum of $R_{C P}$ and $\mathrm{R}_{\mathrm{NP}}$ appeared in $0-10 \mathrm{~cm}$ soil layer. The mean of $\mathrm{R}_{\mathrm{CN}}, \mathrm{R}_{\mathrm{CP}}$ and $\mathrm{R}_{\mathrm{NP}}$ were 10.28 , 10.73, 1.05 (invaded soil), 9.71, 10.05, 1.10 (the uninvaded soil). $\mathrm{R}_{\mathrm{CN}}$ and $\mathrm{R}_{\mathrm{CP}}$ in the invaded soil of Sophora alopecuroides were higher than those in the uninvaded soil, and the $\mathrm{R}_{\mathrm{NP}}$ in the uninvaded soil was slightly higher than that in the invaded soil.

\section{Characteristics of $C, N, P$ concentrations and their stoichiometric ratios in different organs of Sophora alopecuroides}

There are differences in the concentrations of $\mathrm{C}, \mathrm{N}$, and $\mathrm{P}$ in different organs of Sophora alopecuroides (Fig. 3). As shown in Figure 3A, the C concentrations showed an order of leaves $>$ stems $>$ roots in plot-I, II and III, while stem C concentration was slightly higher than that of leaf in plot-IV. There was no significant difference in $\mathrm{C}$ concentration among plot-I, II and III. There was a significant difference in the concentration of $\mathrm{C}$ between leaf and root in plot-IV. As shown in Figure 3B, there was no significant difference in the concentration of $\mathrm{N}$ between leaves and stems in the four plots, and there was a significant difference in root $\mathrm{N}$ concentration between plot-III and IV. As shown in Figure 3C, the leaf $\mathrm{P}$ concentration was significantly higher than the 
stem and root $\mathrm{P}$ concentrations in plot-I. The leaf $\mathrm{P}$ concentration was significantly different from the stem P concentration between plot-III and IV. There was a significant difference in $\mathrm{P}$ concentration between leaf and root in plot-III. There was a significant difference in $\mathrm{P}$ concentration between stem and root in plot-III.
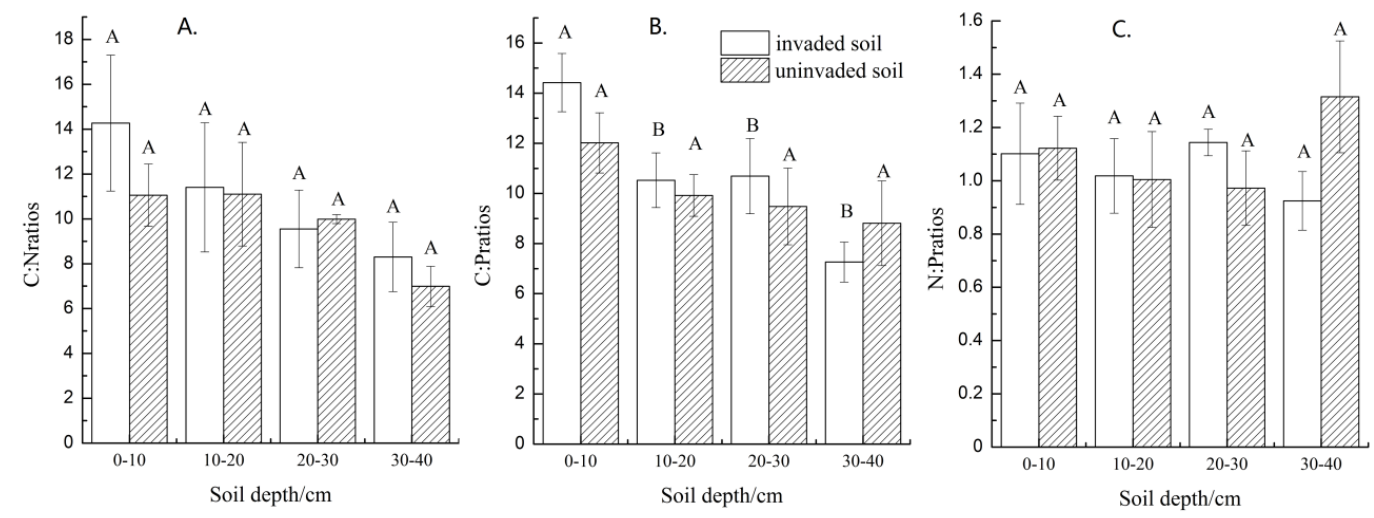

Figure 2. The distribution of $R_{C N}(C: N), R_{C P}(C: P)$, and $R_{N P}(N: P)$ in the soil profile in the invaded soil and in the uninvaded soil. $A$ and $B$ represent significant differences between the invaded soil and the uninvaded soil in the different depth $(P<0.05)$
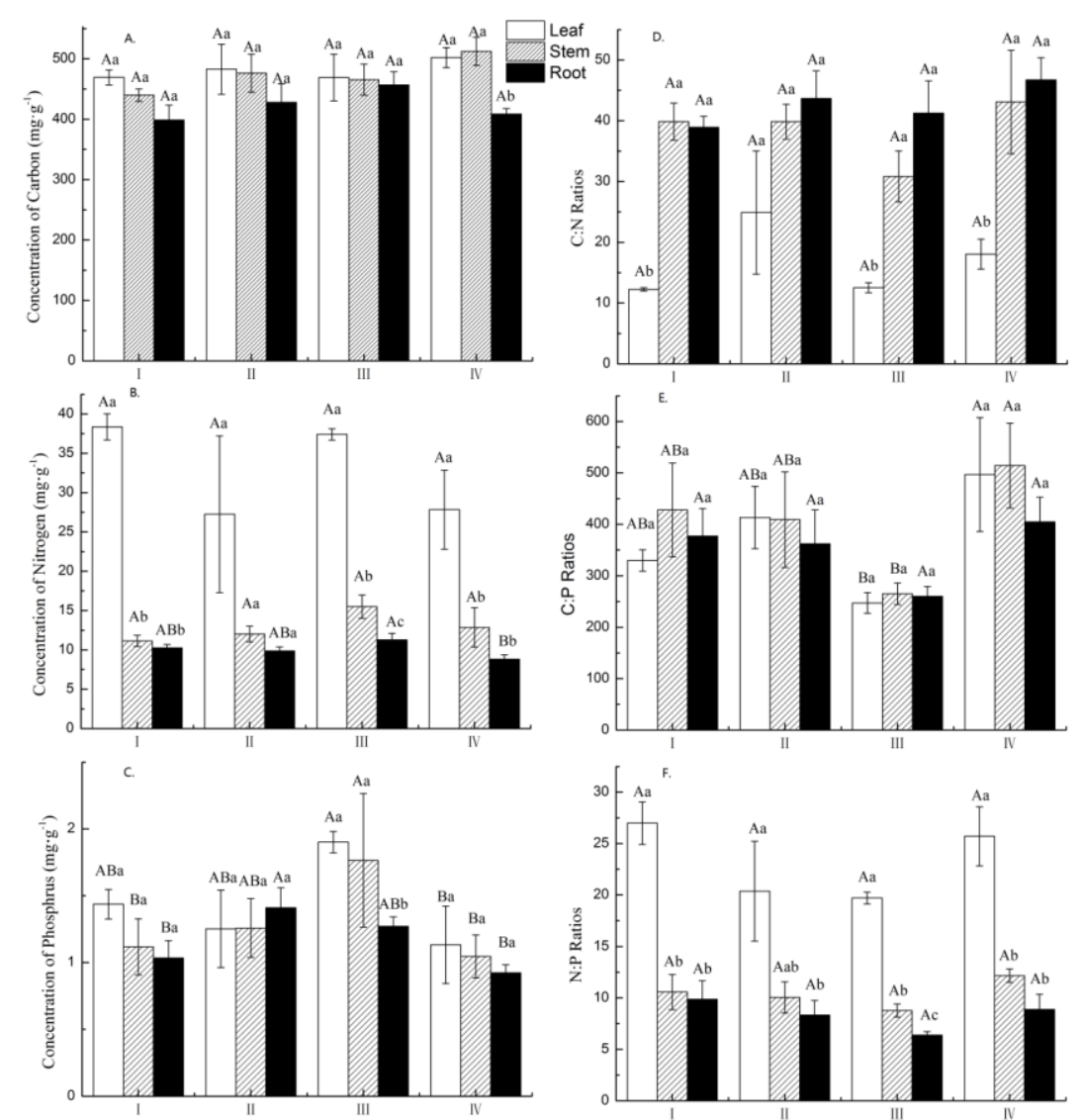

Figure 3. $C, N$, and $P$ concentrations and their stoichiometry in the organs of Sophora alopecuroides in different habitats. A, B and $C$ represent significant differences among organs in different habitats $(P<0.05)$ and $a, b$ and $c$ represent significant differences among the different organs in the same habitat $(P<0.05)$ 
The stoichiometric ratios of $\mathrm{C}: \mathrm{N}, \mathrm{C}: \mathrm{P}$, and $\mathrm{N}: \mathrm{P}$ in different organs of Sophora alopecuroides showed the regular changes. As shown in Figure 3D, the stoichiometric ratio of $\mathrm{C}: \mathrm{N}$ in plot-II, III, and IV showed the trend of roots > stems > leaves. There were significant differences in the C:N ratio between leaf and stem in plot-I, III and IV. There was no significant difference in $\mathrm{C}: \mathrm{N}$ ratio among root, stem and leaf in plot-II. The ratio of the C:N did not differ among the four plots. As shown in Figure 3E, there were significant differences in the $\mathrm{C}: \mathrm{P}$ ratio between the leaf and stem of plot-III and the leaf and stem of plot-I, II and IV. The ratio of the C:P did not differ among the roots, stems and leaves in the four plots. As shown in Figure $3 F$, the N:P ratio were in the order of leaf $>$ stem $>$ root. There was a significant difference in the N:P ratio among root, stem, and leaf in the plot-III, but the ratio of $\mathrm{N}: \mathrm{P}$ did not differ among the four plots.

\section{Correlation between $C, N, P$ concentrations and stoichiometric ratio of Sophora alopecuroides}

As shown in Figure 4, correlation analysis (Fig. 4A, B, C, D) showed that the correlation between $\mathrm{C}: \mathrm{N}$ ratio and $\mathrm{N}$ concentration of Sophora alopecuroides was significantly negative $(P<0.01)$. As shown in Fig. 4E, F, $G, I$, there was a significant negative correlation between $\mathrm{C}: \mathrm{P}$ ratio and $\mathrm{P}$ concentration in plot-I, II, and IV $(P<0.05)$. The correlation between $\mathrm{C}: \mathrm{P}$ ratio and $\mathrm{P}$ concentration was not significant in plot-III $(P>0.05)$. As a whole, the $\mathrm{C}: \mathrm{N}$ and $\mathrm{C}: \mathrm{P}$ ratios increase with the decrease of their corresponding $\mathrm{N}$ and $\mathrm{P}$ concentrations. The logarithmic equation in the figure can clearly show the above correlation. As shown in Fig. $4 I, J, K, L$, there was a significant positive correlation between $\mathrm{N}$ and $\mathrm{P}$ concentrations $(P<0.05)$, There was a significant positive correlation between $\mathrm{N}$ and $\mathrm{P}$ concentrations in plot-III, but there was no significant difference between $\mathrm{N}$ and $\mathrm{P}$ concentrations in plot-II $(P>0.05)$.

\section{Habitat and organ effect on $C, N, P$ concentrations and their stoichiometric characteristics of Sophora alopecuroides}

The effects of organs and habitats on the $\mathrm{C}, \mathrm{N}$ and $\mathrm{P}$ concentrations and their $\mathrm{C}: \mathrm{N}$, $\mathrm{C}: \mathrm{P}$, and N:P ratios of Sophora alopecuroides were quantified by GLM analysis. The $\mathrm{C}, \mathrm{N}$, and $\mathrm{P}$ concentrations and their $\mathrm{C}: \mathrm{N}, \mathrm{C}: \mathrm{P}$, and $\mathrm{N}: \mathrm{P}$ ratios were affected differently by the single factor and the interaction of the two factors. As shown in Table 2, C:N ratio and the $\mathrm{N}$ concentration are mainly affected by the organs, while the $\mathrm{P}$ concentration and $\mathrm{C}: \mathrm{P}$ ratio are mainly affected by the habitats. Organs and habitats had no significant effect on the concentration of $\mathrm{C}$. The interaction between organs and habitats did not differ in $\mathrm{C}, \mathrm{N}$, and $\mathrm{P}$ concentrations and their stoichiometric ratios.

\section{Discussion}

\section{Change of $C, N, P$ concentrations and their stoichiometric ratio in organs of Sophora} alopecuroides

The concentrations of elements and stoichiometric ratios of roots, stems, and leaves of plants vary significantly due to their different functions and storage of nutrients, Leaves are the main aboveground components for plants to absorb and store nutrient elements. Because leaves are the most metabolic aboveground organs, the 
concentrations of $\mathrm{N}$ and $\mathrm{P}$ in leaves are higher than that of roots and stems for storing nutrients (Luo and Gong, 2016). In this study, the concentrations of N and P in Sophora alopecuroides are consistent with the result. The concentration of $\mathrm{P}$ in leaf of Sophora alopecuroides in plot-II was slightly lower than that in stems and roots, and the concentration of $\mathrm{P}$ in soil physical and chemical factors was the lowest. It may be one of the reasons why the concentration of $\mathrm{P}$ in the leaves cannot be replenished. Leaves are the main photosynthetic organ of plants. Leaf $\mathrm{C}$ concentration increased during the peak growing season, and then it is transported to the stem and root. According to the research of Xiao et al., the nutrient content of the stem is generally smaller than that of leaves with the increase of plant biomass in most plants growth process (Xiao et al., 2014). The root is the main organ for the plant to absorb nutrients and transport nutrients. Because root grows underground, photosynthesis does not take place here and cell metabolism ability is not strong. The main function of the root is to transport nutrients and water from the soil, so the accumulation of $\mathrm{C}$ element by root is the least. Zhao et al. (2014) showed that the root $\mathrm{N}$ and $\mathrm{P}$ concentrations change because the elements flow to other organs. In the process of plant growth, the roots are growing. The root maintains its growth by absorbed nutrient elements, and output a lot of nutrients to assist the growth of other organs. The concentrations of $\mathrm{N}$ and $\mathrm{P}$ in roots are relatively lower.
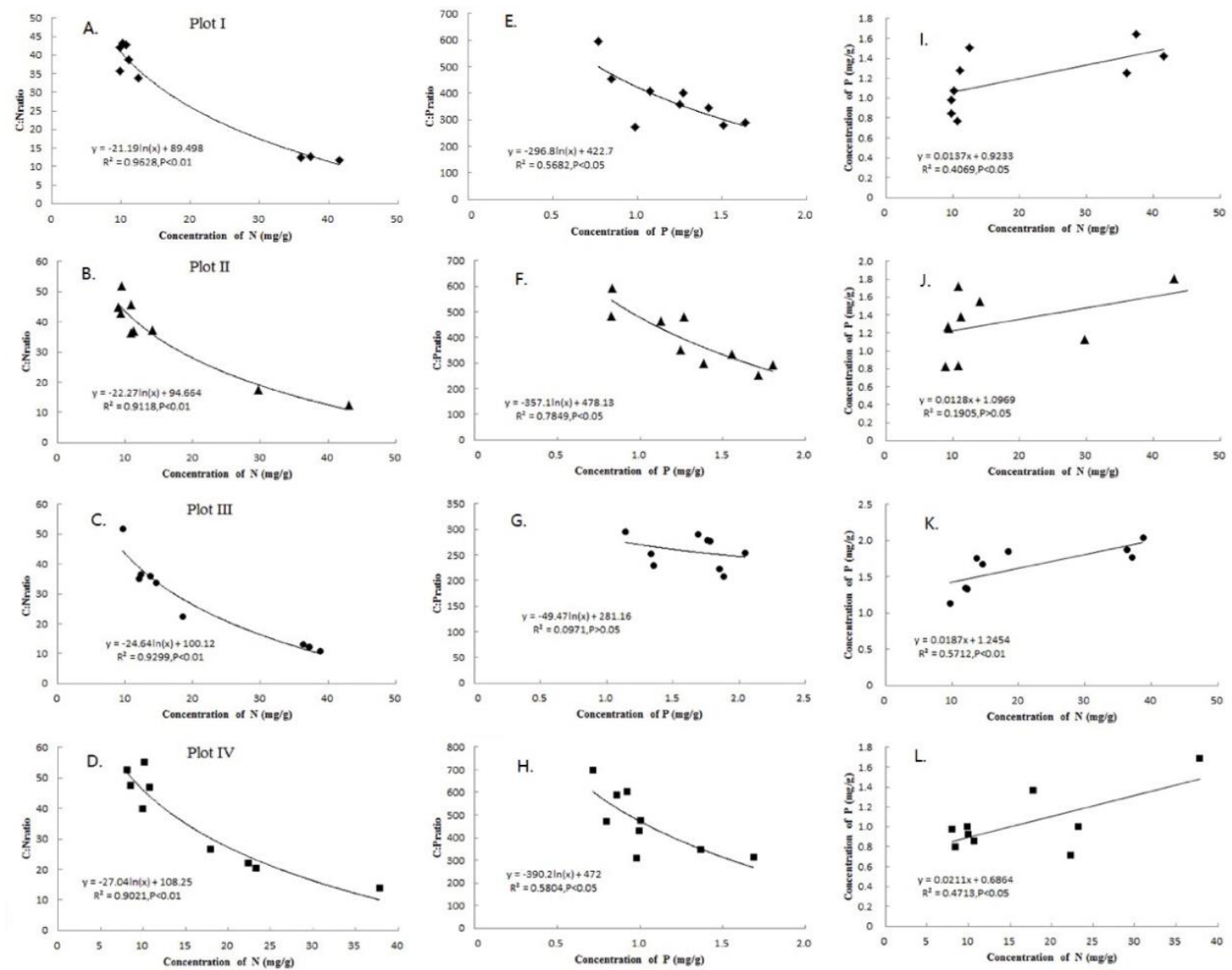

Figure 4. Relationship between the ratio of $C: N$ and $N$ concentration, between the ratio of $C: P$ and $P$ concentration, and between $N$ and $P$ concentration of Sophora alopecuroides in different habitats 
Table 2. GLM analysis of habitat and organ effects on C, N, P concentrations and their stoichiometric characteristics

\begin{tabular}{c|c|c|c|c|c|c}
\hline $\begin{array}{c}\text { Independent } \\
\text { variable }\end{array}$ & $\begin{array}{c}\text { Dependent } \\
\text { variable }\end{array}$ & $\begin{array}{c}\text { Quadratic } \\
\text { sum }\end{array}$ & DOF & Mean square & F & Significance \\
\hline \multirow{5}{*}{ Organ } & $\mathrm{C}$ & 23779.651 & 2 & 11889.826 & 5.920 & 0.080 \\
& $\mathrm{~N}$ & 3655.346 & 2 & 1827.673 & 52.586 & 0.000 \\
& $\mathrm{P}$ & 0.440 & 2 & 0.220 & 2.472 & 0.106 \\
& $\mathrm{C}: \mathrm{N}$ & 4480.742 & 2 & 2240.371 & 31.678 & 0.000 \\
& $\mathrm{C}: \mathrm{P}$ & 17117.127 & 2 & 8558.564 & 0.673 & 0.519 \\
& $\mathrm{~N}: \mathrm{P}$ & 1552.806 & 2 & 776.403 & 62.036 & 0.000 \\
\hline \multirow{5}{*}{ Plot } & $\mathrm{C}$ & 7221.278 & 3 & 2407.093 & 1.199 & 0.332 \\
& $\mathrm{~N}$ & 169.318 & 3 & 56.439 & 1.624 & 0.210 \\
& $\mathrm{P}$ & 1.809 & 3 & 0.603 & 6.782 & 0.020 \\
& $\mathrm{C}: \mathrm{N}$ & 452.333 & 3 & 150.778 & 2.132 & 0.123 \\
& $\mathrm{C}: \mathrm{P}$ & 213173.795 & 3 & 71057.932 & 5.590 & 0.005 \\
& $\mathrm{~N}: \mathrm{P}$ & 113.479 & 3 & 37.826 & 3.022 & 0.049 \\
\hline \multirow{5}{*}{ Organ $\times$ Plot } & $\mathrm{C}$ & 8981.013 & 6 & 1496.835 & 0.745 & 0.619 \\
& $\mathrm{~N}$ & 193.952 & 6 & 32.325 & 0.930 & 0.491 \\
& $\mathrm{P}$ & 0.602 & 6 & 0.100 & 1.129 & 0.376 \\
& $\mathrm{C}: \mathrm{N}$ & 224.739 & 6 & 37.457 & 0.530 & 0.780 \\
& $\mathrm{C}: \mathrm{P}$ & 23314.623 & 6 & 3885.770 & 0.306 & 0.928 \\
& $\mathrm{~N}: \mathrm{P}$ & 46.202 & 6 & 7.700 & 0.615 & 0.716 \\
\hline
\end{tabular}

The ability of the plant to absorb nutrient and assimilate $\mathrm{C}$ can be expressed by $\mathrm{C}: \mathrm{N}$ and $\mathrm{C}: \mathrm{P}$ ratios of leaves, which reflect the productivity that can be achieved by unit nutrient supply and the utilization efficiency of the plant to absorb nutrition. The nutrient limitation of the environment on plants can be shown by the $\mathrm{N}: \mathrm{P}$ ratio. In order to adapt to the changes of the environment, plants will adjust concentrations of the nutrient elements, namely the changes of stoichiometric ratios. The stoichiometric ratios form a certain feedback relationship between the environment and plants (Jiang et al., 2014; Xia et al., 2014; Carrie et al., 2015). Plant N:P ratio reflects the $\mathrm{N}$ and $\mathrm{P}$ nutrient conditions of its environment. It can judge the nutrient supply of the environment for plant growth and the growth rate of the plant ( $\mathrm{Li}$ et al., 2012). In the extreme desert environment, the soil showed a severe $\mathrm{N}$ deficiency, and the concentrations of $\mathrm{N}$ and $\mathrm{P}$ and the ratio of $\mathrm{N}: \mathrm{P}$ in leaves were significantly different (Tao et al., 2015). In this study, we can find that the N:P ratio of leaf was greater than that of other organs. Because of the sampling time in September, the roots and stems of plants are mature and the nitrogen and phosphorus nutrient elements are relatively stable, while the leaves of plants are in the rapid growth stage and the leaves belong to the nutritive organs. Leaves need to consume a lot of phosphorus-rich substances (DNA, ATP, etc.) to meet the needs of plant growth and reproduction process. Therefore, the ratio of N:P in leaves of the same plant is higher than that in roots and stems. The N:P ratio of leaves of herbaceous plants were much higher than that of roots (Wu et al., 2010), which was consistent with the results of this study. 


\section{Stoichiometric ratio and correlation analysis of Sophora alopecuroides in different habitats}

The growth, development, and behavior of organisms are closely related to the concentrations of $\mathrm{C}, \mathrm{N}$, and $\mathrm{P}$ (Dong, 1996). The ratio of $\mathrm{N}: \mathrm{P}$ in leaves can be used as an indicator to judge the nutrient supply of the environment for plant growth (Vitousek et al., 1982; Wassen et al., 1995). When leaf $\mathrm{N}: \mathrm{P}$ ratio < 14, plant growth is mainly limited by $\mathrm{N}$; when N:P ratio > 16, plant growth is mainly limited by $\mathrm{P}$; when $14<\mathrm{N}: \mathrm{P}$ ratio < 16, plant growth is limited by $\mathrm{N}$ and $\mathrm{P}$ together (Venterink et al., 2003; Jiang et al., 2016). In this paper, N:P ratio > 16 in the leaves of Sophora alopecuroides in four habitats showed that the growth of Sophora alopecuroides was mainly limited by $\mathrm{P}$, and there was no significant difference in the ratio of $\mathrm{N}: \mathrm{P}$ in the leaves of Sophora alopecuroides in four habitats. To prevent the spread of Sophora alopecuroides in the pasture, it may be more effective to control the absorption of $\mathrm{P}$. Correlation analysis showed that $\mathrm{C}: \mathrm{N}$ and $\mathrm{C}: \mathrm{P}$ ratios have negative correlation with corresponding $\mathrm{N}$ and $\mathrm{P}$ concentrations, and the logarithmic equation can reflect this changing relationship. The $\mathrm{N}$ and $\mathrm{P}$ concentrations have positive correlation and the linear equation showed this changing trend better (Fig. 4). The positive correlation between $\mathrm{N}$ and $\mathrm{P}$ reflected the relative consistency of the change of the two nutrient elements in the plant, which is a strong guarantee for the stable growth and development of the plant and also one of the most basic characteristics of the plant (Wu et al., 2010).

\section{Habitat and organ effects on $C, N, P$ concentrations and their stoichiometric characteristics}

Stoichiometric characteristics reflect the synergistic and interactive effects of many factors. The changes of stoichiometric characteristics in plants can examine the relationship between plants and the environment and judge the structure, function and stability of the ecosystem in which plants are located (Tao et al., 2017; Gong et al., 2017). The distribution of chemical elements in plant organs is the common result of environment and phylogeny (Tang et al., 2016). In the growth stage, nutritional requirements for Sophora alopecuroides also increased with the improvement of the productivity level. Sophora alopecuroides mainly obtain C through photosynthesis of leaves, so organs have a relatively large impact on $\mathrm{C}$ concentration. $\mathrm{N}$ plays a very important role in the growth and development of plants. In this study area, the nitrogen is insufficient for the growth of Sophora alopecuroides, especially in the roadside habitat. Under this nutrient restriction, Sophora alopecuroides can gradually adapt to the change of $\mathrm{N}$ utilization strategy by adjusting the protein and its metabolite group in organs according to its own growth needs (Shao et al., 2013). Zheng et al. (2013) found that the adaptation mechanism of plants would change in the low-nutrient environment. This is part of survival strategy of Sophora alopecuroides in extreme environment. This is an important strategy of plant growth regulation and material distribution and a result of plant adaptation to the environment. In the process of natural growth, plants adapt to changes in the environment by adjusting the nutrient changes of different organs and their stoichiometric ratios (Ping et al., 2014). Therefore, organs have a greater influence on $\mathrm{C}$ and $\mathrm{N}$ concentrations and $\mathrm{C}: \mathrm{N}$ and $\mathrm{N}: \mathrm{P}$ ratios. The growth of Sophora alopecuroides requires much available $\mathrm{P}$, but its transformation rate of $\mathrm{P}$ element is relatively lower and the external environment can provide sufficient $\mathrm{P}$ source for the growth of Sophora alopecuroides, which make its growth stable. The soil nutrients will 
be reflected in plants and the external environment that affects the absorption of plant nutrients ( $\mathrm{Hu}$ et al., 2014). Therefore, habitats have a greater influence on $\mathrm{P}$ concentration and C:P ratio of Sophora alopecuroides.

\section{Conclusions}

The $\mathrm{R}_{\mathrm{CN}}$ and $\mathrm{R}_{\mathrm{CP}}$ in the profile of Sophora alopecuroides invasion soil changed obviously. $\mathrm{R}_{\mathrm{CN}}$ showed a "ladder" decline. The maximum of $\mathrm{R}_{\mathrm{CN}}$ and $\mathrm{R}_{\mathrm{CP}}$ appeared in the $0-10 \mathrm{~cm}$ soil layer. $\mathrm{R}_{\mathrm{NP}}$ did not change significantly and the maximum appeared in the 20-30 cm soil layer. $\mathrm{R}_{\mathrm{CN}}, \mathrm{R}_{\mathrm{CP}}$, and $\mathrm{R}_{\mathrm{NP}}$ in the profile of Sophora alopecuroides uninvaded soil are relatively gentle. The maximum of $R_{C N}$ appears in the $10-20 \mathrm{~cm}$ soil layer. The maximum of $R_{C P}$ appears in the $0-10 \mathrm{~cm}$ soil layer and the maximum of $R_{N P}$ appears in the $30-40 \mathrm{~cm}$ soil layer. $\mathrm{N}: \mathrm{P}$ ratios $\left(\mathrm{R}_{\mathrm{NP}}=1.05-1.10\right)$ of the soil is far lower than the global average (13.1) (Cleveland and Liptzin, 2007) and the national average (5.2) (Tian et al., 2010). Sophora alopecuroides invaded and uninvaded soils were limited by $\mathrm{N}$.

There are differences in the concentrations of $\mathrm{C}, \mathrm{N}, \mathrm{P}$ and their stoichiometric ratios in roots, stems and leaves differed with habitat. Only the concentration of $\mathrm{N}$ and ratio of $\mathrm{N}: \mathrm{P}$ showed the order of leaves > stems > roots. There was a significant difference in the $\mathrm{C}$ concentration between root and leaf and there was a significant difference in the $\mathrm{C}$ concentration between root and stem in plot-IV. But there was no significant difference in other habitats. There were significant differences in the concentration of $\mathrm{N}$ between leaf and root and there were significant differences in the concentration of $\mathrm{N}$ between leaf and stem in plot-I and IV. There were significant differences in the concentration of $\mathrm{N}$ among the root, stem and leaf in plot-III. There was no significant difference in the concentration of $\mathrm{N}$ among the root, stem and leaf in plot-II. There was no significant difference in the P concentration among the root, stem and leaf in plot-IV. The C:N and N:P ratios of leaf and root were not significantly different among the four habitats. There were significant differences in the leaf and stem C:P ratios between plot-III and IV. The N:P ratio > 16 of leaves in different habitats indicated that the growth of Sophora alopecuroides was mainly limited by $\mathrm{P}$.

Correlation analysis showed that C:N and C:P ratios of Sophora alopecuroides in different habitats were negatively correlated with the corresponding $\mathrm{N}$ and $\mathrm{P}$ concentrations, but there was no significant correlation between $\mathrm{C}: \mathrm{P}$ ratio and $\mathrm{P}$ concentration in plot-III. There was a positive correlation between $\mathrm{N}$ and $\mathrm{P}$ concentration in the four plots. The results showed that the physiological activities of Sophora alopecuroides in different habitats were regulated by $\mathrm{N}$ and $\mathrm{P}$.

The $\mathrm{C}, \mathrm{N}$, and $\mathrm{P}$ concentrations and their C:N, C:P, and N:P ratios Sophora alopecuroides were affected by habitat and organ. $\mathrm{C}: \mathrm{N}$ ratio and $\mathrm{N}$ concentration are mainly affected by the organs, while the $\mathrm{P}$ concentration and $\mathrm{C}: \mathrm{P}$ ratio are mainly affected by the habitat. This is the nutrient utilization strategy of Sophora alopecuroides in different habitats. Sophora alopecuroides adapted to the barren soil environment by $\mathrm{N}$ and $\mathrm{P}$ nutrient utilization strategy. At present, Sophora alopecuroides has become the dominant species of degraded pasture in the Yili valley, resulting in the decline of grassland quality and economic productivity. It is of great significance to study the changes of $\mathrm{C}, \mathrm{N}$, and $\mathrm{P}$ concentrations of organs in various habitats of Sophora alopecuroides for revealing the growth and spread process of Sophora alopecuroides. 
Acknowledgements. This work was supported by the University scientific research program of Xinjiang Uygur Autonomous Region, P. R. China (XJEDU2018Y042).

\section{REFERENCES}

[1] Aerts, R., Chapinf, S. (2000): The mineral nutrition of wild plants revisited: a reevaluation of processes and patterns. - Advances in Ecological Research 30: 1-67.

[2] Ashton, I. W., Hyatt, L. A., Howe, K. M., Gurevitch, J., Lerdau, M. T. (2005): Invasive species accelerate decomposition and litter nitrogen loss in a mixed deciduous forest. Ecological Applications 15(4): 1263-1272.

[3] Carrie, A., Deans, S. T., Behmer, A. K. (2015): The importance of dissolved N:P ratios on mayfly (Baetis spp.) growth in highnutrient detritus-based streams. - Hydrobiologia 742: 15-26.

[4] Cleveland, C. C., Liptzin, D. (2007): C:N:P stoichiometry in soil: is there a "Redfield ratio" for the microbial biomass? - Biogeochemistry 85(3): 235-252.

[5] Dong, M. (1996): Survey, Observation and Analysis of Terrestrial Biocommunities. Standards Press of China, Beijing.

[6] Elser, J. J., Sterner, R. W., Gorokhova, E., Fagan, W. F., Markow, T. A., Cotner, J. B., Harrison, J. F., Hobbie, S. E., Odell, G. M., Weider, L. J. (2000): Biological stoichiometry from genes to ecosystems. - Ecology Letters 3(6): 540-550.

[7] Gong, L., Li, H. L., Liu, Y. T., An, S. Q. (2017): Effect of nitrogen and phosphorus fertilizers on carbon, nitrogen, and phosphorus stoichiometry of oasis cotton in the upper reaches of Tarim River, Xinjiang, China. - Acta Ecologica Sinica 37(22): 7689-7697.

[8] Hu, Q. W., Nie, L. Q., Zheng, Y. M., Wu, Q., Yao, B., Zheng, L. (2014): Effects of desertification intensity and stand age on leaf and soil carbon, nitrogen and phosphorus stoichiometry in Pinus elliottii plantation. - Acta Ecologica Sinica 34(9): 2246-2255.

[9] Jiang, L. L., He, S., Wu, L. F., Yan, Y. F., Weng, S. F., Liu, J., Wang, W. Q., Zeng, C. C. (2014): Characteristics of stoichiometric homeostasis of three plant species in wetlands in Minjiang Estuary. - Wetland science 12(3): 293-298.

[10] Jiang, P. P., Cao, Y., Chen, Y. M., Wang, F. (2016): Variation of C, N, and P stoichiometry in plant tissue, litter, and soil during stand development in Pinus tabulaeformis plantation. - Acta Ecola Sin 36(19): 6188-6197.

[11] Li, Y. Y., Feng, J. T., Zhang, X., Hu, L. F. (2005): Advance in research of chemical ingredients from Sophora alopecuroides L. and its bioactivities. - Acta Agriculturae Boreali-accidental Sinica 14(2): 133-136.

[12] Li, Z., Han, L., Liu, Y. H., An, S. Q., Leng, X. (2012): C, N and P stoichiometric characteristics in leaves of Suaeda salsa during different growth phase in coastal wetlands of China. - Chinese Journal of Plant Ecology 36(10): 1054-1061.

[13] Li, C. J., Xu, X. W., Sun, Y. Q., Qiu, Y. Z., Li, Y. S., Gao, P., Zhong, X. B., Yan, J., Wang, G. F. (2014): Stoichiometric characteristics of C, N, P for three desert plants leaf and soil at different habitats. - Arid Land Geography 37(5): 996-1004.

[14] Liu, Y., Zhao, Y., Munir, Li, W. H. (2017): Canopy seed bank of Sophora alopecuroides L. in Ili River Valley. - Chinese Journal of Ecology 36(4): 910-915.

[15] Lu, R. K. (1999): Methods for Chemical Analysis of Soil Agriculture. - China Agricultural Science and Technology Press, Beijing.

[16] Lu, D. K., Ou, Y. Y., Deng, Y. X., Liu, B., Zhao, Y. (2011): Terrestrial biomass and reproductive allocation characteristics of Sophora alopecuroides L. in Ili River Valley. Xinjiang Agricultural Sciences 48(7): 1333-1338.

[17] Luo, Y., Gong, L. (2016): Stoichiometric characteristics in root, stem and leaf of Phragmites australis in different habitats in the southern marginal zone of Tarim Basin. Chinese Journal of Ecology 35(3): 684-691.

[18] Michaels, A. F. (2003): The ratios of life. - Science 300(5621): 906-907. 
[19] Ou, W. X., Yang, G., Gao, J. H. (2006): Retention effect of wetland for nitrogen and phosphorus nutrients in the coastal zone of Yancheng. - Wetland Science 4(3): 180-188.

[20] Ping, C., Wang, C. K., Quan, X. K. (2014): Influence of environmental changes on stoichiometric traits of nitrogen and phosphorus for Larix gmelinii trees. - Acta Ecologica Sinica 34(8): 1966-1974.

[21] Shang, B. Y., Yang, P., Chen, L., Gao, X. J., Yong, J. J., Zhang, X., Zhao, J. J., Wang, H. Q. (2018): Research on network pharmacology of alkaloids in Sophora alopecuroides. China Journal of Chinese Medica 43(1): 160-167.

[22] Shao, X. X., Li, W. H., Wu, M., Yang, W. Y., Jiang, K. Y., Ye, X. Q. (2013): Dynamics of carbon, nitrogen and phosphorus storage of three dominant marsh plants in Hangzhou Bay coastal wetland. - Environmental Science 34(9): 3451-3457.

[23] Shi, F. Y., Qiu, M. N., Li, G. Z., Zhang, G., Wu, C. C., Lu, H., Zhao, B. Y. (2019): Research progress on the resource status, chemical composition, toxicity, exploitation and utilization of Sophora alopecuroides. - Heilongjiang Animal Science and Veterinary Medicine 13: 34-38.

[24] Tang, G. R., Zheng, G. W., Wang, X., Zhu, Y. Q. (2016): Effects of tourism disturbance on the ecological stoichiometry characteristics of $\mathrm{C}, \mathrm{N}$ and $\mathrm{P}$ of the vegetation and soil in Kanas scenic area. - Pratacultural Science 36(8): 1476-1485.

[25] Tao, Y., Zhang, Y. M. (2015): Leaf and soil stoichiometry of four herbs in the Gurbantunggut Desert, China. - Chinese Journal of Applied Ecology 26(3): 659-665.

[26] Tao, W., Wu, J. W., Liu, C. F., Fang, L., Liu, Y., Yuan, J. H., Li, J. (2017): Response of stoichiometric homeostasis and allometric scaling in halophyte Suaeda heteroptera Kitag. to simulated nitrogen and phosphorus deposition. - Journal of Hydroecology 38(4): 1826.

[27] Tian, H. Q., Chen, G. S., Zhang, C., Melillo, J. M., Hall, C. A. S. (2010): Pattern and variation of C:N:P ratios in China's soils: a synthesis of observational data. Biogeochemistry 98(1/3): 139-151.

[28] Venterink, H. G. M. O., Wassen, M. J., Verkroost, A. W. M. (2003): Species richnessproductivity patterns differ between N-, P-, K-limited wetlands. - Ecology 84(8): 21912199.

[29] Vitousek, P. (1982): Nutrient cycling and nutrient use efficiency. - The American Naturalist 119: 553-572.

[30] Wang, Z. N., Yang, H. M. (2013): Response of ecological stoichiometry of carbon, nitrogen and phosphorus in plants to abiotic environmental factors. - Pratacultural Science 30(6): 928-931.

[31] Wang, W. Q., Xu, L. L., Zeng, C. S., Gong, C., Zhang, L. H. (2011): Carbon, nitrogen and phosphorus ecological stoichiometric ratios among live plant-litter-soil systems in estuarine wetland. - Acta Ecologica Sinica 31(23): 7119-7124.

[32] Wassen, M. J., Olde Venterink, H. G. M., de Swart, E. O. A. M. (1995): Nutrient concentrations in mire vegetation as a measure of nutrient limitation in mire ecosystems. - Journal of Vegetation Science 6: 5-16.

[33] Wu, T. G., Wu, M., Liu, L., Xiao, J. H. (2010): Seasonal variations of leaf nitrogen and phosphorus stoichiometry of three herbaceous species in Hangzhou Bay coastal wetlands, China. - Chinese Journal of Plant Ecology 34(1): 23-28.

[34] Xia, C., Yu, D., Wang, Z., Xie, D. (2014): Stoichiometry patterns of leaf carbon, nitrogen and phosphorous in aquatic macrophytes in eastern China. - Ecological Engineering 70: 406-413.

[35] Xiao, Y., Tao, Y., Zhang, Y. M. (2014): Biomass allocation and leaf stoichiometric characteristics in four desert herbaceous plants during different growth periods in the Gurbantünggüt Desert, China. - Chinese Journal of Plant Ecology 38(9): 920-940.

[36] Yang, J. X., Yu, F. (1998): Advance on Sophora alopecuroides. - Tian Jin Pharmacy 10(1): 43-46. 
[37] Yu, H. L., Li, Y. Z., Fan, J. W., Zhong, H. P. (2016): Leaf N and P contents of different functional groups in relation to precipitation and temperature in China Grassland Transect. - Chinese Journal of Ecology 35(11): 2867-2874.

[38] Zeng, D. P., Jiang, L. L., Zeng, C. C., Wang, W. Q., Wang, C. (2013): Reviews on the ecological stoichiometry characteristics and its applications. - Acta Ecologica Sinica 33(18): 5484-5492.

[39] Zhao, Y. F., Xu, F. L., Wang, W. L., Wang, L. L., Wang, G. X., Sun, Y. P., Bai, X. F. (2014): Seasonal Variation in Contents of C, N and P and Stoichiometry Characteristics in Fine Roots, Stems and Needles of Larix principis-rupprechtii. - Chinese Bulletin of Botany 49(5): 560-568.

[40] Zheng, Y. M., Yao, B., Wu, Q., Hu, B. H., Hu, Q. W. (2013): Dynamics of leaf carbon, nitrogen and phosphorus of two dominant species in a Poyang Lake wetland. - Acta Ecologica Sinica 33(20): 6488-6496. 